\title{
Sharing Minds During Pregnancy and 20 Years Later- A parental Interview-Based Study
}

\author{
Monica Hedenbro* \\ Department of Child and Youth Psychiatry, Karolinska Institute, Sweden
}

*Corresponding author: Monica Hedenbro, Department of Child and Youth Psychiatry, Karolinska Institute, Sweden.

To Cite This Article: Monica Hedenbro. Sharing Minds During Pregnancy and 20 Years Later- A parental Interview-Based Study. Am J Biomed Sci \& Res. 2021 - 14(3). AJBSR.MS.ID.001988. DOI: 10.34297/AJBSR.2021.14.001988.

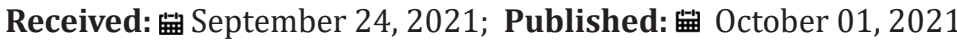

\begin{abstract}
Background: The aim of this study was to explore parents' experience of having been part of the Swedish Sharing Minds project, which started during pregnancy and ended with an interview when the offspring were young adults. The aim was to explore, and reflect back on, their expectations of becoming first-time parents.
\end{abstract}

Methods: Twenty couples were enrolled during standard prenatal visits and invited to an interview about their thoughts and feelings on becoming parents. These took place when the women were 24 weeks' pregnant with their first baby. The families were followed on a number of occasions over a period of 16 years and an interview was conducted when the offspring were 20 years old. The focus of this study was the couples' reflections on the early interviews and meetings, especially the one during pregnancy, and what they had meant to them.

Results: The results of the 20-year interview indicated that conducting the interview with the couples during pregnancy supported their relationship, as they shared their expectations with each other. This provided an important foundation for their relationship as co-parents over the following years, regardless of whether they had very similar of different thoughts or feelings. They also strongly emphasized the importance of being followed by the researcher as their child got older, as they liked the fact that interest was being shown in them and in their child. Couples who were divorced or had parted both found that taking part in the project at regular intervals helped them to focus on their priorities and maintain their co-parenting skills.

Conclusion: The results highlighted the importance of putting more emphasis on seeing newly pregnant partners and talking about their feelings about becoming parents for the first time. This can help families to stay together and can also enable them to continue to co-parent, even if they split up or divorce.

Keywords: Interaction; Reflecting; Mind; Expectant Parents; Maternity Health Care; Co-Parenting; Triad; Interviews

\section{Introduction}

Becoming a parent for the first time changes people's lives dramatically and marital satisfaction often declines during this period [1]. During this transition, the marital dyad is expanded to include the co-parenting triad and the mother-infant and fatherinfant dyads. Co-parenting is a triadic interaction in which the mother and father may support, or undermine, each other's position regarding their child. It is different to the marital relationship dyad, which does not necessarily involve the child [2]. Marital and parental subsystems have been described as interrelated. Feldman [3] found that paternal involvement could decrease maternal depression and anxiety, increase reciprocity in both dyadic units and increase harmony in the co-parenting triad. Another study found that how a husband communicated with his wife when she was six months' pregnant was associated with how involved he was with their three-month-old baby. This communication was also positively correlated with the infants smiling or crying [4]. McHale and Cowan [2] studied how dysfunctional marital interactions during conflicts made co-parenting more hostile and competitive. A harmonious, supportive marriage made parents more sensitive, responsive and involved when they were co-parenting. Therefore, the quality of the interaction between parents has a spillover effect, which transferred their moods, emotions or behaviors to their child 
and affected their later development [5]. One example of this risk was when spouses showed contempt or withdrew from one another [6]. The Emotional Security Theory [7] argues that children face risks when their security is threatened by conflicts between their parents, or they don't think that their parents will solve them.

Another study [8] found parents were more likely to withdraw from their infant at eight months of age if they had relationship issues during pregnancy. These associations continued for up to two years of age, especially for the father. Furthermore, good coparenting relationships meant that infants engaged more easily in triadic interactions and received more sensitive and adjusted responses than infants who grew up with parental conflicts [9,2]. Finally, the synchronized interaction in the triad depends on smooth parental interaction and coordination [10]. Studies from our team found that synchronized interaction at four and 16 years was related to higher social competence in children [11,12]. A study by Borelli et al emphasised [13] that we need to look more closely at how parents see the mental state of their partner and how that affects their co-parenting and relationship. Reflective functioning is a major variable that demonstrates associations with parentchild attachment and interactional quality. Borelli et al showed that a partner's reflective functioning may be an important way of understanding how a couple's relationship functions, together with their parental well-being [13].

Widarsson et al. [14] reported that expectant mothers and fathers both wanted more parental involvement in their pregnancy and that the best support for the father was the mother. Expectant parents both wanted the father to be more involved in their baby's healthcare and for healthcare professionals to place a greater focus on the whole family. In Sweden, most women visit Governmentfunded Maternity Health Center regularly during pregnancy, starting when they are 12 weeks' pregnant. The fathers of the women's babies or their partner accompany them to some visits if they can. Their children then attend Child Health Centre for regular development visits and routine health care until they start school at the age of six. These specialist clinics review the somatic and emotional development of the mothers and their children. They also provide the parents with support during pregnancy and with their child's development. This system provides healthcare professionals with special opportunities to support parents and to understand when extra psychological interventions are needed. These include the chance to see a psychologist. Most of the prenatal meetings with the nurses are only attended by the mothers but sometimes the father/partner takes part. We now know that fathers/partners can also develop pregnancy-related depression, but it is not as easy to identify them and offer them treatment [15]. There are also few established routines and methods that focus on talking to the father/partner and couple than there are for the expectant mother.
Talking to fathers/partners is important, as it helps to support their development into parenthood, but it is not necessary to do this as a couple. It could be argued that places where prenatal services are offered should be called family health care centres rather than Maternity Health Centres. This would stress their family-centred profile and be more inviting to the father/partner. Ståhl et al. [16] described how the nurses and the child health centre welcomed a family-oriented perspective. In another study they stated that the newly established individual counselling they had developed had deepened their family perspective [17]. In Sweden the health care system provides regular check-ups during pregnancy and after birth. The role that fathers have played in Swedish families has undergone big changes in the last 50 years. Most mothers now work outside home and the father/partner plays an active role in childrearing.

Couples can share 480 days and the majority of this is paid at $80 \%$ of their income. However, both the parents are very involved in taking care of the child. Research has highlighted the need to involve fathers/partners and healthcare professionals try hard to include them during pregnancy check-ups. However, it has been hard to find a way to meet these needs and make the midwives feel comfortable about what support can be given [18]. One recent initiative has increased the nurses' focus by providing an individual session for the fathers/partners 3-5 months after birth [17,19]. We use the Edinburgh Postnatal Depression Scale (EPDS) in our Stockholm-based unit as well as in other parts of the country to screen for postnatal depression. Research has described various forms of perinatal mental distress and how they could affect the fetus and the child in the long term [20-23] as well as the early interaction between the parent and child [24-26]. It is difficult to know where to draw the line between mental illness, depression and emotional adjustment problems during this transitional phase. That is why parents should have easy access to psychological support and counselling. The aim of this study was to explore the parent's experience of a project that started during pregnancy and was carried out when their child reached 20 years of age. It specifically looked at their expectations of becoming parents for the first time and what role the project played in that process.

\section{Method}

This paper reports the findings of Sharing Minds, a prospective, longitudinal study which started with parental interviews and questionnaires in the $24^{\text {th }}$ week of pregnancy and followed 20 families until the child was 20 years old. An important element of the larger study was the use of the Lausanne Trilogue Play (LTP) paradigm. that was developed by Dr Elisabeth Fivaz-Depeursinge and has been described in detail in papers by Fivaz-Depeursinge et al. $[2,3]$. The LTP uses video sessions to assess triadic interactions 
between an infant and its mother and father, where the mother, the father and the infant are working together on a task but playing different roles in that task. In our study the newborn baby and his or her mother and father were videotaped in LTP situations when they were three and nine months old and later at 18 and 48 months of age. The author also met the family at 7 and 15 years of age using appropriate questionnaires and interviews to understand the family situation and social development of the child. Results are reported in earlier published papers [11]. The aim of the Sharing Minds study was to understand how the parents were thinking of becoming parents. The author therefore met with the parents during pregnancy for an interview with the couple together. The questions focused on how they were thinking of their becoming parents. When the offspring was 20 years old the questions in the interview was reflecting back on having become parents and on being part of this project.

\section{Participants}

The sample comprised 20 couples who became first-time parents in 1996 and 1997. They were sequentially recruited by midwifes working in a Mother Health Centre in a suburb of Stockholm with a very varied population. Recruitment took approximately one month and only two couples did not want to take part. The 20 women had a mean age of 27 years (range 2132) and 10 of them had completed college or university education, eight had completed senior high school and two had completed lower or compulsory school, The men's mean age was 30 years (range 24-42) and nine had completed higher education, five senior education and six compulsory educations. Eighteen of the 20 women were Swedish, one was originally from Finland and one was from Brazil. Nineteen of the 20 men were Swedish, and one man was originally from Australia. The mean age of the parentsto-be was representative of Swedish parents-to-be, but the level of education was higher. We noted that $42 \%$ of the couples were married and the rest were living together. It is normal in Sweden for committed, unmarried couples to live together and plan to become parents. There were 12 boys and eight girls in the study. One girl was born 10 weeks premature, and we used her corrected age in the study.

\section{Interview Format}

All 20 expectant couples took part in the interviews during the $24^{\text {th }}$ week of pregnancy and were interviewed together after they had provided signed, informed consent. The interviews took place in the researcher's clinic and the interviews were taped. At the time of the 20-year follow up, six couples had separated. Three of these families did not want to visit the clinic to be interviewed, but two of the couples agreed to take part in telephone interviews. The third did not take part at all but was seen at 16 years interview. The other three families came to the clinic to be interviewed, with two being interviewed as couples and the other couple being interviewed separately. The child they were expecting at the time of the first study joined the interviews as well as their siblings. After the interview they took part in a family conversation as well as a family task that is not part of this paper. All the interviews were taped and transcribed verbatim. The separation rate for the couples in this longitudinal project was $30 \%$. The corresponding figure for divorce rate in Stockholm during the study period was 58\%.

\section{Pregnancy Interviews}

The pregnancy interviews were carried out with couples and focused on how they saw themselves and their partners as parents and how they thought it would feel when their baby was born. They were also asked to draw symbols that represented their new family. They were interviewed again when their offspring was 20 years old to reflect on the impact of the early interview.

\section{The 20-year Follow Up}

The focus of this study was the interviews with the parents when their child had reached 20 years of age. During those interviews I asked them how they had felt coming to the latest follow-up visit and if they remembered the questions they had been asked during pregnancy. I also asked them how important it had been for them to take part in the project from various perspectives. These were their relationship with their partner and as a parent and individually. Inductive thematic analysis was chosen to analyse, structure and present the results [27]. The interviews varied in length from 60 80 minutes. The same questions were asked at all the interviews and were aimed at both partners. The meetings also included other family interactions that were not the focus of this study and will be reported separately. There were several steps to the analysis. The first step was listening to the interviews several times and then choosing areas that carried special memories for the parents. The focus was to find responses that gave answers to my questions. As the couples were very comfortable when they were talking and sharing, they provided a lot of material and finding the most relevant parts was quite challenging. These sections were focused upon, the themes were created, checked against the original interview and related to the study questions.

\section{Ethical Permission}

The original pregnancy study and the 20-year follow-up study were approved by the Ethical Committee at Karolinska Institutet (Dnr 95-289;00-050;01-447) and by the Regional Ethical Council in Stockholm (Dnr 2011/384-31/5, Dnr 2015/1043-32). 


\section{Results}

\section{How did you Feel Coming Here Today?}

Most of the couples felt good about attending the 20-year interview, regardless of whether they were still together. As one said: "We like it, it feels familiar and nice". Both the men and women expressed good, and similar, feelings. The women tended to talk more about how they felt taking part in their pregnancy interview, as it was when they were starting their new family. The men agreed, but they also said that it was interesting to take part in the ongoing project, because they got asked questions or were given tasks that makes them reflect on parenthood. The women added that they always left the interviews with a good feeling and that it gave them things to talk about. One of the six divorced families stopped taking part in the project when their daughter was seven years old as she was diagnosed with autism and had clinical interventions from the researcher instead. However, they were still invited to take part in the follow up and did attend in an interview at 16 years with the similar aim as the 20-year interview. Another couple divorced when their child was seven years old and she lived half of the time with her mother and half the time with the father. The father was difficult to contact and did not want to come to the 20-year follow up with his daughter. He was very angry when I finally reached him and said he had found the separation and lack of cooperation hard and was going to move far away. In their interviews the mother talked about the bitterness the father had experienced after the divorce and the girl expressed very strong emotions of sadness and worry. The mother had come to the interview as they were in crisis and thought I could help. It turned into a therapy session, as the mother needed help to communicate with her daughter and support her.

Two other families had experienced difficulties with children that had been diagnosed with Asperger syndrome and attention deficit hyperactivity disorder. They had struggled since at least preschool and when they were asked to take part in this follow up the two mothers did not initially want to engage in the process but agreed to talk over the phone and so did also the fathers. Interestingly both the mothers expressed frustration and sadness that their family life had developed this way, even though they were part of this project. In contrast to these four divorced couples, another couple that had divorced when the child was about three years of age used the opportunity to come to the 20-year follow up as a whole family. They reflected on taking part in the study in the same way as the families that had stayed together. They liked coming back to the place they had previously visited and expressed positive feelings of being there together and reflecting once again on their family life and how things had developed. The couple still shared a strong bond and had worked with their the new partners and children to create one big family. Another couple that had divorced when the child was three years old and had new partners, wanted to come together as a family. They shared memories from earlier visits during the years. They had enjoyed it and also mentioned how different becoming parents had been from what they thought it would be. They also reflected on the joy of having their baby and reflected on how they had managed to work together to provide the best for their son. The son was very comfortable being in the triad.

\section{What has been the Most Important Aspect of Taking Part in this Project?}

There were 14 families that were still living as complete family units and 10 of those said that taking part in the study had a strong positive impact on them. The parents spoke about the importance of taking part in the project and one stated that it was "especially important for us as partners and expectant parents". As one parent said: "All these question that you asked were something we never had thought of ourselves. They were questions that made us think and we kept them in mind and reflected on them. It was good for us to talk more about the questions when we got home. It helped us to think differently over the years". One father remembered a question that made him understand that this baby would be close to his mother in the beginning and that he [ the father] would probably feel left out. He said, "I am so glad you asked because it was hard for me, but I was aware that could happen". The parents were aged 40-50 during the 20-year interviews and they were in their 20s and 30s when they took part in the pregnancy interviews. One father, who had talked about communication as a central issue when his partner was pregnant, said: "We got so much help from the interviews, as it made us communicate, even when we thought differently. It was like a safe place where we could express differences that we could continue talking about at home". None of the divorced parents reflected in a similar way. In fact, two of the mothers were frustrated that taking part had not helped them when their children were diagnosed with Asperger syndrome and attention deficit hyperactivity disorder. As earlier mentioned, they expressed frustration that being part in the project had not prevented these problems.

Continuity was something that most of the parents talked about and their visits became very familiar to them. A couple of women said it was like coming to visit a "grandmother or a relative". As one said: "You were always so interested in us and our child" This was also true for three of the divorced families that came to the 20-year interview. The mothers, in particular, talked about how important it was as a new parent for someone to take an interest in how their child was developing and the sort of person they were becoming. One mother said; "You paid an interest in us as parents as well and how we felt and experienced having become a parent. You were engaged". Another said: "It was always nice and had a good atmosphere when 
we came here". The mothers were much more emotional when they were talking about what it had meant to be part of the project. Two of the mothers mentioned that they did not have relatives close to where they lived and that meeting regularly in this project in some respects this helped. One mother said, it filled the "emptiness" of not having relatives close by. They were different ages and had nothing in common other than being part of this project.

Most of the mothers and fathers, including the divorced couples, said that there were lots of questionnaire to fill in, but they did not remember the precise details. The parents were asked if there were any particular things that they remembered from the early meetings with the author. During the pregnancy interviews they had been asked to make drawings that symbolized what they thought their new family of three would look like when the baby arrived. When they attended the three-year interview, 14 of the families mentioned those drawings as a strong memory and they mentioned them at the 20-year interview when we talked about what they remembered. Some recalled that they had the same image as their partner and some said that they had different images. But they agreed that it was a useful way of seeing how their other half was thinking. They remembered the similarities and differences and one mother said that their different perceptions reflected the fact that they had struggled with their relationship. The couples said that it was important to try and see how their partners thought about the same subject, in this case their new baby. The fact that they shared these thoughts was more important than the different symbols in their drawings. The memories were still there and cause it was drawings they had seen they evoked stronger memories now 20 years later. The other strong memory that was mentioned by all the families was the chair that the baby sat in when they performed the Lausanne Triadic Play interaction task at two and three months of age and, in particular, how their baby interacted with them. One father summed up the feelings of most of the parents when he said: "He was just sitting there, so small and young, but so able to interact and communicate. I became so aware of the small signs of communication he was giving". The fathers tended to be more explicit when they talked about his. Their awareness of our meetings before this level of interaction were vaguer. For example, the parents hardly remembered the meeting at four weeks, before they had first Lausanne Triadic Play. The mothers said that during that first month they were much more busy finding the best way to take care of their new babies.

\section{Discussion}

A major impression gained from the interviews, that ranged from the $24^{\text {th }}$ week of pregnancy to when the offspring were 20 years-old, was that it was important for couples to share both positive and negative feelings. The parents who took part said that the most important thing was to know how their partner was thinking, regardless of whether they had similar or different thoughts and feelings. This raises questions about how the needs that came out of the interviews should be met during pregnancy. Most of the meetings at the Maternity Health Centre are with the mother, but the fathers/partners are welcome to attend other prenatal and postnatal visits so that they can get to know the nurse, ask questions and get information. However, none of these visits focused on their relationship and becoming parents together. Since 2019 there has been a new initiative in Sweden [19], whereby the fathers/partners are invited to attend an individual visit when the baby is between 3-5 months old.

This study was carried out by the therapist who met with the parents from 24 weeks of pregnancy to 20 years after the birth and the aim was to assess the parent's memories of the early stages of the study. The aim of the pregnancy interviews was to understand how the expectant parents were thinking and further meetings explored their early interactions with their new baby. When the parents visited the researcher as families after 20 years, it was natural to explore whether those first meetings had been helpful. A qualitative method was used and themes were identified from the transcribed interviews. The material was treated similarly, regardless of whether or not the couples were still together. At the same time, it was important to highlight any special issues that they had been struggling with if they lived apart. The major question explored by this study was whether seeing the couples together during pregnancy helped them when they became parents for the first time.

The author's role in this longitudinal project was not just as a researcher, but as an interviewer and clinician and to some extent somebody who paid a close interest in the couples, their child and the family as a whole. This intervention might have influenced the outcomes, but it is not possible to know what would have happened if the intervention had not existed. However, three important points have emerged from this study. First, information was gathered in a data to fill in number of ways. The parents completed questionnaires individually and although these provided useful information, they did not share them with each other The questions that emerged during the interventions and interviews were much more important to them, as they could share the responses. The only real references they made to the questionnaire at the 20-year follow up was that there were a lot of. The couples were much more interested in talking about the exchanges between them at the sessions and the impact those had on them. Secondly, we discussed the drawings they had made at 24 weeks of pregnancy and how they symbolised becoming a family. During the follow-up interviews they did not focus on the fact that both of them had drawn a picture. 
What was important to them was that they had shared the pictures with each other and discussed what they meant. Third, when the parents took part in the follow-up interview at 20 years they talked about the important moments when they put their child in the chair at two and three months of age and interacted with them. It became an intervention for them that the child already at this age was so capable interacting with them. A number of home visit pilot schemes have been in high-risk areas of Sweden to reach families early and provide them with parenting and relationship support after their first baby was born [28]. The nurses who carried out these visits during the child's first two years worked together with a family counsellor from social services. The questions that are asked, and the communication with the couple, could provide a good blueprint for seeing all new parents, even if it is in child health centres and not at home. We need to place more emphasis on seeing partners together and talking about the changes they are going through together.

\section{Strengths and Limitations}

There were limitations to this study as it was a small sample. A qualitative analysis was used as it was such a small number of families. A limitation could also be that the responses from the men and women was clustered into themes. Alternatively, they could be looked upon as individual reflections.

\section{Conclusion}

This research highlights how early seamless support plays an important role as couples become parents for the first time. Having a baby is a stressful period, both individually and as a couple, and we need to make it easy for expectant parents to find help. We already have instruments like the EPDS to identify when mothers are not feeling well and Swedish child health centres are now holding individual sessions for fathers or partners after their baby has been born. The divorce rate is as high as $50 \%$ in Stockholm, Sweden's capital city. It is clear that there needs to be a stronger focus on relationships at this life-changing time. This study used ongoing interviews and observed how parents interacted with their child at various points. Seeing the couple together during pregnancy and after the birth, was very useful and this was confirmed by the parent's feedback. Interviews could clearly be carried out by nurses, and these would have great potential when it comes to helping expectant parents to share their thoughts and feelings as they go through the process of becoming parents.

\section{References}

1. Cowan CP Cowan PA (1992) When partners become parents. New York: Basic Books.
2. McHale JP, Cowan P (Eds) (1996) Understanding How Family-level Dynamics Affect Children's development: Studies of Two- Parent Families. San Francisco: Jossey Bass.

3. Feldman R (2007) Maternal versus child's risk and the development of parent-infant and family relationships in five high-risk populations. Dev Psychopathology 19(2): 293-312.

4. Shapiro FA (2005) Examining relationships between the marriage, mother-father-baby interactions, and infant emotion regulation Dissertation Abstracts International: Section B: The Sciences and Engineering 65(B): 3750.

5. Katz LF, Gottman JM (1996) Spillover effects of marital conflict: In search of parenting and co-parenting mechanisms. In J McHale, P Cowan (Eds) Understanding how family-level dynamics affect children's development: Studies of two-parent families 74: 57-76.

6. Gottman JM, Katz LF, HoovenC (1997) Meta-emotion. Lawrence Erlbaum.

7. Cummings M, Davies PT (2010) Marital conflict and children: an emotional security perspective. Guilford Press.

8. Gallegos MI, Murphy SE, Benner AD, Jacobvitz DB, Hazen NL (2016) Marital, parental and whole-family predictors of toddler's emotion regulation: The role of parental emotional withdrawal. J Family Psychol 31(3): 294-303.

9. Fivaz Depeursinge E, Corboz Warnery A (1999) The Primary triangle. A Developmental Systems View of Mothers, Fathers and Infants.

10. Hedenbro M (2019) Exploring Family Perspectives using Interaction Guidance. Focus on the Family pp: 6-19.

11. Hedenbro M, Rydelius PA (2014) Early interaction between infants and their parents predicts predicts social competence at the age of four. Acta Paediatr 103(3): 268-274.

12. Hedenbro M, Rydelius PA (2018) Infant's turn-taking skills in triadic interaction correlate with social competence at age 15. Acta Paediatr 103(3): 268-274.

13. Borelli JL, Slade A, Pettit C, Shai D (2020) I "get" you babe: Reflective functioning in parents transitioning to parenthood. J Social Personal Relation.

14. Widarsson M, Engström G, Tydén T, Lundberg P, Hammar LM (2015) 'Paddling upstream': Father's involvement during pregnancy as described by expectant father's and mother's. J Clin Nur 24(7-8): 10591068.

15. Johansson M, Svensson I, Stenström U, Massoudi P (2017) Depressive symptoms and parental stress in mothers and fathers 25 months after birth. J Child Health Care 21(1): 65-73.

16. Ståhl M, Kristensson Hallström O, Skoog, Vilhelmsson A (2019) 'So, the circle has grown'-Child Health Services nurse's experiences of giving parental interviews with nonbirthing parents. Scand Caring Sci 34(1): $139-147$

17. Wettergren B, Blennow M, Hjern A, Söder O, Ludvigsson JF (2016) Child health systems in Sweden. The J Pediatrics 117: 187-202.

18. Burefors L (2013) Prospective cardboard couples-Experiences during pregnancy and needs In the meeting with the midwife. Fathers to be. Experiences during pregnancy and needs when meeting the midwife. Degree project 15 higher education credits Reproductive and perinatal health Sahlgrenska Academy. Department of Caring Sciences and Health.

19. Bergström M (2019) Individual parent conversations. NordmarkLindberg I (edn.), Rikshandboken Barnhälsovård (National Manual of Child Health Services). 
20. Howard LM, Piot P, Stein A (2014) No health without perinatal mental health. Lancet 384(9956): 1723-1724.

21. O Hara MW, Wisner KL (2014) Perinatal mental illness: Definition, description and aetiology. Best Pract Res Clin Obstetrics Gynaecol 28(1): 3-12.

22. Massoudi P (2013) Depression and distress in Swedish father's in the postnatal period-prevalence, correlate, identification, and support University of Gothenburg, faculty Social Sciences.

23. Johansson M (2019) Postpartum depression, depressive symptoms and parental stress in mothers and fathers 25-30 months after childbirth: A family perspective. Linen University.

24. Baker ED, Jaffee SR, Uher R, Maughan B (2011) The contribution of prenatal and postnatal maternal anxiety and depression to child maladjustment. Depression Anxiety 28(8): 696-702.
25. Field T (2010) Postpartum depression effects on early interactions, parenting, and safety practices: A review. Infant Behav Develop 33(1): $1-6$

26. Fredriksen E, Langemar P (2008) Qualitative research methodology in psychology. Stockholm, Liber AB.on Soest T, Smith L, Moe V (2019) Parenting stress plays a mediating role in the prediction of early child development from both parent's perinatal depressive symptoms. J Abnormal Child Psychol 47(1): 149-164.

27. Langemar P (2008) Qualitative research methodology in psychology. Stockholm Liber AB.

28. Tiitanenn MK, Lindber L, Burström B, Marttila A (2019) Strengthening resilience through an extended postnalat home visiting program in a multicultural suburb in Sweden: fathers striving for stability. BMC Public Health 19(1). 